\title{
ESCUELA PARA PADRES: UNA VISIÓN PARA LA REFLEXIÓN SOCIAL Y CIUDADANA DESDE LOS DIVERSOS ACTORES
}

\author{
Lipselotte de Jesús Infante Rivera ${ }^{1}$ \\ José Manuel Armada Pacheco ${ }^{2}$ \\ Fernando Viterbo Sinche Crispin ${ }^{3}$
}

Recibido 05/04/2019 Aceptado 30/05/2019

La presente investigación propone generar una nueva visión de la escuela para padres en torno a la reflexión social desde los diversos actores. La epistemo - metodología se trabajó bajo un enfoque cualitativo, paradigma sociocrítico y el método Investigación Acción, se estableció comunicación con los informantes clave utilizando la observación y entrevista en profundidad como técnicas para la recolección de la información, para el análisis de los datos se realizó una triangulación y contrastación. Entre las conclusiones o reflexiones se obtuvo que hay entornos familiares con grandes necesidades que requieren de orientación para cumplir de manera acertada la tarea y enorme responsabilidad de ser padres, y que además compartan con los docentes de una forma asertiva.

The present investigation proposes to generate a new vision of the school for parents around the social reflection from the different actors. The epistemology - methodology was worked under a qualitative approach, sociocritical paradigm and the Action Research method, communication was established with key informants using observation and in-depth interviews as techniques for the collection of information, for the analysis of the data was made a triangulation and contrast. Among the conclusions or reflections was that there are family environments with great needs that require guidance to fulfill the task and the enormous responsibility of being parents, and also share with teachers in an assertive manner.

DOI

https://doi.org/10.15366/didacticas2019.20.004

1. Universidad Continental. lipselotte_2@hotmail.com linfante@iibec.org.mx

2. Universidad Continental jarmada@continental.edu.pe

3. Universidad Nacional de Huancavelica. fernando.sinche@unh.edu.pe
PALABRAS CLAVE

Escuela para padres; Reflexión Social y Ciudadana; Actores educativos y sociales

\section{KEYWORDS}

School for parents, Social and Civic Reflection, Educational and social actors 


\section{INTRODUCCIÓN}

La educación es el mayor reto de los padres hacia sus hijos, por cuanto ha de garantizar que éste se desarrolle integralmente y se pueda vincular a la sociedad y su demanda. Es decir, que se integre y pueda desenvolverse como un individuo sano y pueda cumplir funciones que coadyuven al cambio social en todos los aspectos. Desde muy temprana edad se ha de velar que esto suceda, para tener la precaución y la convicción de que a futuro todo se va a lograr de acuerdo a lo planeado. Se supone que los hijos aprenden, se acepta esta idea como válida, sin embargo, no es tarea solo de los docentes, ya que se considera que el ámbito familiar es el que mayor influencia tiene sobre el niño. En el ideal de aprendizaje, se tiene la creencia de que se aprende a partir de patrones familiares (paternos, maternos), y ellos a su vez aprendieron de sus propios progenitores y así en una cadena.

Pero, a la hora de evaluar la formación recibida, lo cierto es que muchos han recibido una educación paterna deficiente. Los abuelos hicieron lo mejor posible, pero también son fruto de una cadena formativa imperfecta. Cada quien aprende a su manera y conforma la planificación para el crecimiento de sus hijos de forma diferente, o por lo menos esto es lo que mejor ha de pasar. Siempre y cuando el modelo seguido no sea el más ideal para el sano crecimiento del individuo. Tal como lo M. Dolores Grau, profesora de psicología en la Universidad Católica de Valencia en el artículo titulado: Escuela de padres: un programa de formación/prevención "no hay padres perfectos sino hombres y mujeres que tienen a su cargo la crianza de unos hijos y que ejercen su rol de paternidad según su socialización, sus creencias y sus expectativas" (p. 6).

Se requiere de una intuición y formación propia a través de la relación y compartir de los hijos para que los padres puedan desarrollar su mejor forma de enseñar a sus hijos. Además, el interés de los padres es indispensable en este aspecto. Los padres necesitan aprender de manera formal e informal. Se precisa adquirir entrenamiento y habilidades para realizar su tarea. Y este entrenamiento básicamente se hace con los hijos. Las épocas van cambiando, y con ello el modelo de cada generación ha de cambiar, porque no es igual la crianza que se tenía hace décadas atrás con la que se tiene en la actualidad, cuando la globalización es el modelo a seguir para los jóvenes.

Es indispensable que se tomen en consideración, las estrategias que permitan un mayor acercamiento y alcance en torno a las necesidades de los hijos. Con respecto a lo anterior, la escuela para padres se vislumbra como una respuesta al deterioro que se ha devenido en las relaciones familia-escuela y entre padres e hijos. Tomando en consideración que la escuela para padres se define según Fresnillo, V; Fresnillo, R y Fresnillo, M (2000) como un espacio de información, formación y reflexión dirigido a padres y madres, sobre aspectos relacionados con las funciones parentales. Es un recurso de apoyo a las familias con menores para que puedan desarrollar adecuadamente sus funciones educativas y socializadoras, y superar situaciones de necesidad y riesgo social; es uno de los programas de carácter preventivo que contribuyen a modificaciones de conductas y a la adquisición de pautas saludables de dinámica familiar (p. 9). 
Se trata entonces de relacionarse con el entorno educativo de los hijos, de hacer un paréntesis que sea en beneficio de su bienestar y desarrollo educativo - integral del mismo. No se pretende con esto referir que se va a enseñar a ser padres, pero si mejores amigos, consejeros y conductores encargados de la buena crianza de los hijos. Es aprender nuevas funciones de acuerdo a situaciones que se presenten en cualquier ámbito, de saber cuál es la mejor forma de resolver para que se aproveche lo mejor posible. Sería pues, generar en los padres una nueva visión que tome como punta de partida la reflexión de ser mejores cada día y apoyar sin menoscabo de la integridad paterna o materna.

Esta situación de que enseñen a los padres a ser padres, no es bien vista por muchos de ellos, ya que todos creen que se la saben todas cuando se trata de la relación y crianza de sus hijos, lo que pone aún más difícil el contexto de proporcionar una forma de guiar no de enseñar en relación a esta tarea tan difícil de llevar una excelente relación "padre-hijo". Esto se observa en varias instituciones educativas cuando los padres son llamados a conformar cualquier asociación o una escuela para padres y algunos se rehúsan, anteponiendo como excusa el factor tiempo, apatía, entre otras evasivas.

Generar una nueva visión de la Escuela para padres en torno a una reflexión social y ciudadana desde los diversos actores, es para los estudiantes una de las formas que puede contribuir a superar obstáculos que se derivan de la falta de orientación y tiempo para la atención de algunos padres hacia sus hijos, por lo que se han de promover el asistencialismo y nuevas posibilidades que sean coherentes con la realidad actual. Y, por otro lado, también están contribuyendo con los docentes que en oportunidades se sienten agobiados por el hecho de llevar solos la formación de los estudiantes que tienen a su cargo.

Cabe destacar, que a lo largo de los últimos años se han observado varias instituciones educativas, y se evidencia una disminución la calidad de las costumbres hogareñas que formaban parte de los principales valores morales y cívicos. Ya que, se ha demostrado en los últimos tiempos una conducta muy particular y hasta con disruptividad en los niños dentro del aula de clases y en sus horas de recreo o receso, no realizan las tareas que les son asignadas, no obedecen instrucciones a la hora de realizar alguna actividad guiada, no mantienen el respeto y las buenas costumbres durante las horas académicas.

Para toda la situación antes mencionada, se establecieron mesas de trabajo conformada en dos grupos: docente-docente y docente-padres. Esto con la finalidad de que se detectaran las fallas y debilidades posibles y de esta manera, analizarlas para lograr encontrar sus causas principales y generar ideas adecuadas a la realidad, con las que, poniéndose en práctica se alcanzara una mejor relación familiar y sobre todo con los padres dentro del entorno escolar y aún más allá, el de la sociedad. Ya que esto posiblemente se debe a una falla dentro del núcleo familiar, donde existe una mala comunicación entre los miembros que la conforman, ausencia de reglas, falta de disciplina y sobretodo carencia de atención a las necesidades del niño. Por lo que todos estos aspectos influyen directamente en las actitudes y aptitudes del niño fuera de su hogar. 
La atención hacia los hijos es una suprema necesidad para ellos, de parte de sus padres, por lo cual se reitera que se han de emitir nuevas formas de dirigir las orientaciones familiares dentro de sus núcleos. Esto se observa, tanto a nivel local, como a nivel nacional y mundial, debido al proceso de globalización que ha afectado numerosas familias y que ha traído consigo aportes tanto positivos como negativos, una de las causas que originan la problemática es la llamada sociedad tecnológica que ha separado a las familias viviendo en el mismo hogar. La crisis económica ha logrado que madre y padre deban trabajar simultáneamente para poder asumir la carga familiar en torno al aspecto financiero.

Existe una falla en el sistema educativo que se puede observar casi en toda Latinoamérica que no les permite avanzar en concordancia con lo que se pretende alcanzar. En ese sentido, es indispensable que se tomen en consideración algunos elementos constituyentes de una calidad educativa excelente, considerando que uno de estos es precisamente la integración y observación de los padres en las acciones de sus hijos en la escuela, para que a partir de allí se realicen acciones diagnósticas, preventivas y/o correctivas; estas últimas no son las que se quisieran realizar, ya que no se quiere que los hijos caigan en escenarios no deseados. Con respecto a esto, Núñez, M (2013) refiere lo siguiente:

muchos colegios e instituciones intentan suplir la necesidad que los padres tienen de formación, no obstante, fallan a la hora de implementar un sistema adecuado para otorgar lo que pretenden al faltar: (a) Programas adecuados para efectivamente formar. (b) Recursos diferenciados para entregar a los padres, entendiendo las diferentes edades de los hijos y las características de las familias. (c) Continuidad. No es lo mismo una charla de vez en cuando a un programa eficiente y continuo. (d) Profesionales preparados. Ese es uno de los elementos débiles, puesto que no se trata de teorías aprendidas en contextos universitarios, sino también contar con la experiencia de ser padres para poder transmitir adecuadamente lo que se pretende enseñar. Cuando estos elementos no se ordenan adecuadamente, entonces, las llamadas "escuelas para padres", quedan sólo en "buenas intenciones", que son actividades realizadas para calmar las conciencias antes que algo efectivo (s/n. p).

Lo anterior se puede interpretar como aquellas intenciones que en oportunidades se realizan en las instituciones educativas, pero que casi siempre quedan en papeles o en solo ideales que se pretenden realizar y que, por falta de apoyo o sistematización, no se logran. Esto es, lo que todos los padres y escuelas quisieran tener en un "todo integrado", y no es que no se pueda, sino que no se manifiestan las intenciones por parte de los padres y otras veces por parte de los docentes.

La participación de la cual se ha hecho referencia se basa en la escuela de padres como un programa o plan de conformación y consolidación de una escuela para padres, cuya perspectiva es el desarrollo de la comunidad, donde los padres reconozcan la importancia de esa proyección a través de la participación en mesas de trabajos centrados en temas que les conciernen, e intervienen específicamente en la orientación de sus hijos y las acciones que han de seguir para que se desarrollen sanamente y de forma integral. 


\section{Propósito General}

Generar una nueva visión de la Escuela para padres en torno a una reflexión social y ciudadana desde los diversos actores en las instituciones educativas.

\section{Propósitos Específicos}

Explorar los elementos que constituyen la escuela para padres en función de una óptima actuación y el predominio de una buena praxis de orientación.

Plantear un esquema de la escuela para padres en pro del beneficio del colectivo educativo y social de la institución.

Reflexionar sobre las proyecciones del esquema y su función dentro de la institución con la perspectiva de establecerse en la excelencia educativa.

\section{JUSTIFICACIÓN}

La escuela para padres es uno de los elementos que ha de estar presente en todas las instituciones escolares, a fin de garantizar el desenvolvimiento tanto de los estudiantes como de los docentes, y además de hacer una integración de los padres y representantes en las acciones pedagógicas de sus educandos. En ese sentido, se justifica la presente investigación, ya que promueve un esquema que contribuye a que se tenga esa relación entre los diversos actores y que se mantenga en el tiempo.

En lo que respecta a la parte social, es importante considerar, que se complementan los cuadros de los diferentes estatutos, que intervienen socialmente con la integración de los padres y la comunidad en general. En lo educativo se justifica el estudio por cuanto indica que se lleve a cabo un esquema que sugiere la actuación por parte de los actores educativos, siempre involucrando la parte externa que se constituye con los padres y representantes.

Las orientaciones políticas en el manejo de escuelas para padre al parecer no ha sido la más acertada, por lo que se requiere de políticas más contundentes para el beneficio de todos y que promuevan y fortalezcan el desarrollo de ideas creativas a través de alternativas como manuales normativos y esquemas con temas preparados para ser trabajado con los padres.

La relevancia en el orden de lo económico es indiscutiblemente un elemento importante, ya que con la realización de éste estudio se garantiza la afluencia en estatus financiero. Lo que se pretende es que el estudiante pueda avanzar con la ayuda de los padres en integración con la escuela, y de esta forma ahorrarse el hecho de que éste caiga en repitencia o deba cambiarlo de institución. Es decir, si se vela porque el estudiante tenga una mejor calidad educativa, se pueden preservar muchas situaciones. Así mismo, el hecho 
de que se pueda ayudar a elevar la calidad de la educación contribuye con las etapas de acuerdo a las edades de los niños (as).

Con el seguimiento de un programa educativo, se puede enfocar gran parte de la atención en fortalecer los vínculos familia-escuela para que se generen alternativas y herramientas necesarias para crear mayor motivación y participación de los padres, lo que aumenta la autoestima y confianza de los estudiantes, considerando el entorno socio-cultural de las familias. Además, ayuda a la comunidad a fomentar los valores morales y éticos para una sociedad más justa, ya que la buena educación familiar e intelectual es parte fundamental un entorno adecuado.

\section{METODOLOGÍA}

\section{Matriz Epistémica}

Al momento de hacer un abordaje epistemo-metodológico en la investigación cualitativa, todos los elementos son importantes y uno de ellos es la llamada matriz epistémica, desde donde se puede orientar el proceso investigativo a través del cual se guía al investigador. En todo ese recorrido, el sujeto investigador ha de tener presente que las posturas filosóficas que componen el paradigma por el cual se aborda la investigación, van a contribuir con la declaración de su postura y de las manifestaciones encontradas en el camino.

Para la declaración epistémica del paradigma, se hace necesario que se desglosen cada una de sus dimensiones tales como: la epistemología, axiología, ontología, gnoseología, teleología. Tomando en consideración, que la dimensión epistemológica se refiere a los tipos de conocimiento, tácito y explícito, que forman el conocimiento de cualquier persona, grupo u organización. Se expresa la epistemología en el presente trabajo de investigación, como el fundamento que se obtiene de experiencias y formación académica para la realización del programa de la escuela para padres. Esto es la base de ese conocimiento que se necesita para saber los elementos que componen el programa, los principios, objetivos y temas que se pueden tomar en cuenta para ello.

Por otro lado, la dimensión axiológica de la actividad humana apunta hacia los principios valorativos de los padres y representantes y de todos los actores educativos como tal, para demostrar interés, responsabilidad, amor y sentido de pertenencia entre otros, que pueden contribuir a la orientación necesaria para la creación del programa de escuela para padres.

La dimensión ontológica hace referencia a la interacción de los niveles de conocimiento individual o grupal. Es así como se puede interiorizar el conocimiento de los actores educativos en función de una comprensión de lo nuevo, en donde se logra una transmisión de conocimientos para la orientación sobre el programa de escuela para padres y que se pueda mantener para el futuro de la institución y su proyección en optimización de la calidad educativa. 
Por su parte, la dimensión gnoseológica se concibe como el poder percibir y discriminar las complejas relaciones donde el conocimiento se produce, se distribuye y es apropiado. Se concibe la parte gnoseológica del presente estudio como las ansias del "saber", que por medio de los referentes teóricos se puede derivar en ese estado del arte que se requiere o es necesario para asumir una postura intencional en la realización del programa base de escuela para padres.

En relación a la dimensión teleológica, que no es más que el fin que se persigue en este estudio, es pues generar una nueva visión de la escuela para padres en torno a una reflexión social y ciudadana desde los diversos actores, llámese docentes o padres y representantes.

El método utilizado fue el de Investigación Acción Participativa, IAP de aquí en adelante ya que supone una transformación en la forma en que los padres y/o representantes toman las acciones o actividades pedagógicas de sus representados, es decir, la casi ausencia de ellos en la institución. El método es participativo porque los sujetos investigados participan como coinvestigadores en todas las fases del proceso: planteamiento del problema, recolección de la información, interpretación de la misma, planeación y ejecución de la acción concreta para la solución del problema y evaluación posterior sobre lo realizado. Asimismo, es de destacar, que la investigación se enmarcó en el paradigma sociocrítico que es el que se relaciona con el método IAP. Para recolectar la información se trabajó con tres sujetos significantes los cuales proporcionaron los datos relevantes para el estudio; las técnicas e instrumentos para la aprehensión de la información fue la observación y la entrevista en profundidad a los 3 sujetos y como tratamiento de análisis de dicha información se realizó una triangulación y contrastación.

\section{RESULTADOS}

Se realizó en esta investigación un análisis interpretativo posterior a la recolección de la información de los tres informantes clave, en donde cada uno proporcionó lo concerniente a las preguntas realizadas por la investigadora en su espacio y momentos diferentes. Esto, aseguró que se pudieran extraer las categorías del estudio y se pudieran definir para su posterior contrastación. De la misma forma, esa interpretación llevó a la realización de la visión endógena de la investigadora, así como del programa de escuela para padres en la institución.

\section{Estructuras individuales y General}

ENTREVISTA Al SUJETO SIGNIFICANTE \#1, profesora. Este proceso se llevó a cabo en las instalaciones de la institución, luego de la hora de salida de los estudiantes, como una forma precavida de tener el tiempo, la disposición e interés en dar las mejores respuestas a fin de obtener datos importantes para el estudio. 

\begin{tabular}{l}
\hline Texto \\
\hline ENTREVISTADOR: Buenas tardes profe, vamos a sentarnos por aquí en las sillas de los \\
niños para ponernos cómodas y hacerle la entrevista de la cual le hablé hace un \\
tiempo. Es para lo de mi estudio de la escuela para padres. \\
SuJETO 1: Claro colega, con mucho gusto te voy a decir lo que sé y lo que te pueda \\
ayudar. Ah, gracias por elegirme para tu estudio jajajajajaja.... \\
ENTREVISTADOR: ok, comienzo entonces. ¿Cuántos años tiene trabajando con niños \\
pequeños?
\end{tabular}

SUJETO 1: bueno amiguita, ya son 11 años que egresé como profesional de la docencia, pero con niños pequeños tengo más tiempo, porque ya hacia trabajos de suplencia antes de graduarme y de comenzar a trabajar aquí. Así que la experiencia es mucha. Uff...

ENTREVISTADOR: que bueno profe. Y cómo veo que tiene la experiencia entonces me puede decir ¿qué tal el trato con los padres de sus estudiantes a lo largo de su trabajo? SUJETO 1: uy, a veces bueno, a veces maloooo. Porque tú sabes que hay padres llevaderos, responsables y que están pendiente pues, de la cuestión en la escuela, pero hay otros que hay que cargarlos definitivamente arriados y eso es tedioso. Con todo eso uno tiene que lidiar en esta profesión. Los padres creen que este es el cuidado diario de los hijos y no el sitio donde vienen a formarse. Es terrible!!!

ENTREVISTADOR: si claro. Y sobre los niños, ¿qué me puede decir de su comportamiento? ¿Cómo es?

SUJETO 1: ay no. jajajajaja

ENTREVISTADOR: ¿Por qué la risa, son muy buenos o son malos, dígame a ver?

SUJETO 1: ah pues, si todos los años escolares salen más terribles que obedientes y disciplinados. Tienen mala conducta, mal comportamiento. Y uno les Dice que hagan silencio o se comporten de mejor forma y no entienden, como si no los educaran en su casa. Yo sé, que aquí tenemos responsabilidad, pero desde la casa se inculcan los principios mija y parece que estos de ahora no tienen nada.

ENTREVISTADOR: ¿tiene alguna experiencia o situación en particular de ese comportamiento de los niños?

SUJETO 1: jajajajaja. De esa cabuya, tengo un rollo. Una vez, un niñito le estaba pegando a una niña y fui a mediar en la situación y el niñito ha volteado manita y me tiro un taco que me lo pego durísimo cerca del cuello. Le cité al representante y al otro día tenía a un tigre en la puerta diciéndome cualquier cantidad de cosas antes de escucharme. ¿Tú has visto?

ENTREVISTADOR: bueno, son situaciones que se presentan en el quehacer docente. ¿Y cómo arregló esa situación?

SUJETO 1: tuve que armarme de paciencia y hablar de forma muy calmada con la señora. Pero después de escucharle la bocota que trajo. Le dije que se calmara y me escuchara para poder resolver. Aparte de eso, llegó la otra señora mamá de la niña que salió lesionada en la pelea y ahí me las vi feas porque hasta se querían agarrar de las greñas porque el niño le pegó a la niña sin motivo. Pero al fin, tuve que hacer papel de psicóloga, orientadora y de todo para que no se pusiera peor la cosa.

ENTREVISTADOR: menos mal que se arregló todo a lo bien entonces. ¿Y qué opina sobre un programa que ayude en ese tipo de situaciones?, algo así como una escuela para padres, en donde se los oriente para la mejor conducta de sus hijos, es decir para una buena crianza pues.

SUjETO 1: no sé si funcionaría, pero la idea está muy buena, siempre y cuando los padres asistan, porque la verdad es que son más dejados, o sea, algunos actúan como si no les importara la educación y comportamiento de sus hijos.

ENTREVISTADOR: Bueno, gracias profe!!!

SuJETO 1: de nada amiga. Cualquier cosa me avisas.
Categorías

Responsabilidad

Disciplina

Valores

Resolución de conflictos

Integración familiar 
ENTREVISTA Al SUjETO SIGNificAnTE \#2, representante de una niña de la institución. Es abogada, pero no ejerce su profesión. Esta entrevista fue realizada en la institución, donde se pautó un encuentro en el cual se sintiera más a gusto.

\begin{tabular}{|c|c|}
\hline Texto & Categorías \\
\hline $\begin{array}{l}\text { ENTREVISTADOR: Hola buen día. Gracias por venir a ayudar con este proceso. } \\
\text { SUJETO 2: bueno profe, ojalá fortalezca todo lo bueno y deseche lo malo, lo que no } \\
\text { queremos. } \\
\text { ENTREVISTADOR: cuénteme, ¿cómo ve el proceso de aprendizaje de su hija? } \\
\text { SUJETO 2: Yo no soy docente, pero veo que la hija mía tiene un avance muy bueno. } \\
\text { Cuando la inscribí, ya estaba un poco adelantada porque nosotros en la casa la ponía- } \\
\text { mos a hacer tareas. Ya está en el nivel de egresar y me parece que está súper avan- } \\
\text { zada. } \\
\text { ENTREVISTADOR: que bien. ¿Y el comportamiento de ella, cómo lo ve? } \\
\text { SUJETO 2: ella es una niña muy obediente y responsable con sus cosas. Yo digo que } \\
\text { Dios nos premió con esta bendición, porque los cuentos que escucho de algunas ma- } \\
\text { dres es que sus hijos son terremotos. Ay no, ésteeee yo no quisiera tener esas feas } \\
\text { experiencias conmigo. } \\
\text { ENTREVISTADOR: ¿y a qué cree que se deba ese comportamiento de los otros niños? } \\
\text { SUJETO 2: a mi manera de ver las cosas tiene que ser por falta de atención y educación } \\
\text { profe, porque dígame usted, si esos padres ahora no pasan tiempo con sus hijos y no } \\
\text { saben ni siquiera qué hacen o dejan de hacer en la escuela, cómo van a pedir un buen } \\
\text { comportamiento. Aparte de eso, está el ejemplo de nosotros como padres que debe- } \\
\text { mos darle a los hijos. Si ellos nos ven haciendo cosas indebidas van a copiar ese ejem- } \\
\text { plo, y si decimos malas palabras también lo van a hacer igual, por lo tanto, está de } \\
\text { parte nuestra que esos niños crezcan viendo lo mejor. } \\
\text { ENTREVISTADOR: correcto. ¿Pero, de qué forma cree usted que se pueda remediar } \\
\text { esas situaciones? } \\
\text { SuJETO 2: ah bueno, dándoles mayor importancia a la crianza de los hijos. Poniéndole } \\
\text { cuidado, y trabajan todo el día, bueno que se planifiquen para tener el tiempo que ne- } \\
\text { cesitan los niños. Porque eso es así, cuando uno no se da cuenta de los hijos, ellos } \\
\text { crecen prácticamente solos y sobre todo agarran malas costumbres de otros mucha- } \\
\text { chitos y uno ni se da cuenta. } \\
\text { ENTREVISTADOR: ok. Gracias reina por tu colaboración. } \\
\text { SujETo 2: de nada maestra. Estoy para ayudarle siempre que pueda. }\end{array}$ & $\begin{array}{l}\text { Cuidado } \\
\text { Paradigma }\end{array}$ \\
\hline
\end{tabular}


Triangulación y contrastación de la información

\begin{tabular}{|c|c|c|c|}
\hline Cat. & Sujeto 1: Profesor & Teorías & $\begin{array}{l}\text { Resumen conclusivo del } \\
\text { investigador }\end{array}$ \\
\hline 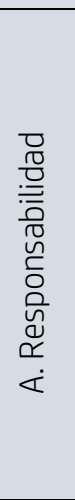 & $\begin{array}{l}\text { Refiere que hay unos } \\
\text { padres que son respon- } \\
\text { sables y están atentos } \\
\text { a las acciones pedagó- } \\
\text { gicas de sus hijos. Y } \\
\text { otros que definitiva- } \\
\text { mente hay que moti- } \\
\text { varlos para que tengan } \\
\text { obligación y responsa- } \\
\text { bilidad con los niños. }\end{array}$ & $\begin{array}{l}\text { Wester, J (2008) refiere que el } \\
\text { concepto de responsabilidad in- } \\
\text { cluye, una dimensión psicosocio- } \\
\text { lógica, en tanto tiene en cuenta el } \\
\text { sentimiento de responsabilidad } \\
\text { como resorte emocional individual } \\
\text { del sentirse afectado por el otro y } \\
\text { como capacidad culturalmente } \\
\text { construida de evaluar consecuen- } \\
\text { cias de las propias acciones y de } \\
\text { atribuirse la obligación de hacerse } \\
\text { cargo" (p.3). }\end{array}$ & $\begin{array}{l}\text { Tiene razón el sujeto } 1 \text { cuando } \\
\text { expresa que los padres han de } \\
\text { ser responsables de las activida- } \\
\text { des educativas de sus hijos, y } \\
\text { más aún cuando se encuentran } \\
\text { en la primera etapa. Así mismo, } \\
\text { el autor refiere que es de atri- } \\
\text { buirse u obtener obligación con } \\
\text { algo o alguien. Pues en este } \\
\text { caso la responsabilidad es con el } \\
\text { entorno familiar y los hijos. }\end{array}$ \\
\hline 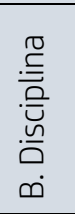 & $\begin{array}{l}\text { Expresa que hay niños } \\
\text { más desobedientes. } \\
\text { Que les falta un poco } \\
\text { de disciplina. }\end{array}$ & $\begin{array}{l}\text { La disciplina según Hernández, C } \\
\text { y López, J (2002) se compone de } \\
\text { obediencia o de un comporta- } \\
\text { miento sometido a reglas (p. 22). }\end{array}$ & $\begin{array}{l}\text { Hay que hacer cumplir las nor- } \\
\text { mas de convivencia y reglas que } \\
\text { se derivan para un buen com- } \\
\text { portamiento, de esta forma se } \\
\text { evidencia la disciplina. }\end{array}$ \\
\hline 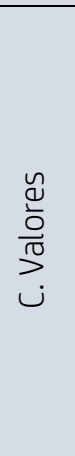 & $\begin{array}{l}\text { Dice que los principios } \\
\text { deben venir forjados } \\
\text { desde el hogar. Com- } \\
\text { para los valores de an- } \\
\text { tes con los de ahora y } \\
\text { dice que no los tienen }\end{array}$ & $\begin{array}{l}\text { Fischer, G (1992) refiere que un } \\
\text { valor "es una concepción explícita } \\
\text { o implícita de lo deseable, especi- } \\
\text { fica de un individuo o caracterís- } \\
\text { tica de un grupo y que orienta a } \\
\text { las modalidades y el sentido de su } \\
\text { acción" (p. 29) }\end{array}$ & $\begin{array}{l}\text { Los valores son formados desde } \\
\text { el principio en el hogar, y es lo } \\
\text { que trata de evidenciar el sujeto } \\
\text { 1. Por otro lado, el autor refiere } \\
\text { que es una característica interna } \\
\text { o externa del individuo, y orienta } \\
\text { las acciones del mismo. Lo que } \\
\text { la investigadora considera como } \\
\text { un modelo ejemplar si los pa- } \\
\text { dres y representantes los incul- } \\
\text { caran desde temprana edad. }\end{array}$ \\
\hline 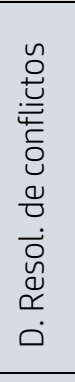 & $\begin{array}{l}\text { Resuelve conflictos a } \\
\text { través de la comunica- } \\
\text { ción, la escucha efec- } \\
\text { tiva y la calma en todo } \\
\text { momento. }\end{array}$ & $\begin{array}{l}\text { Valdez, M y Guerra, E (s/f) refieren } \\
\text { que la resolución de conflictos es } \\
\text { una ciencia interdisciplinaria y } \\
\text { transversal que recoge el saber } \\
\text { teórico y práctico acumulado por } \\
\text { diferentes disciplinas y experien- } \\
\text { cias a lo largo de la historia, espe- } \\
\text { cialmente en su perspectiva con- } \\
\text { temporánea (p. 1). }\end{array}$ & $\begin{array}{l}\text { La vía más idónea para resolver } \\
\text { los conflictos tanto en el ámbito } \\
\text { educativo como en cualquier } \\
\text { otro es la negociación verbal. }\end{array}$ \\
\hline 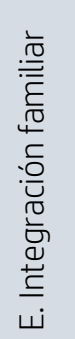 & $\begin{array}{l}\text { Refiere que la asisten- } \\
\text { cia de los padres es im- } \\
\text { portante. Que al pare- } \\
\text { cer no les importa la } \\
\text { educación de sus hijos. } \\
\text { Que deben integrarse a } \\
\text { las acciones de la es- } \\
\text { cuela. }\end{array}$ & $\begin{array}{l}\text { En las Jornadas de Estudio de In- } \\
\text { tegración Familiar (2011) se ex- } \\
\text { presó en torno a la integración fa- } \\
\text { miliar que "es evidente la impor- } \\
\text { tancia del apoyo familiar y la cer- } \\
\text { canía de su red de apoyo social } \\
\text { como factor de integración" (p. } \\
\text { 138). }\end{array}$ & $\begin{array}{l}\text { La integración familiar tiene en } \\
\text { el ámbito escolar su símbolo } \\
\text { más claro del logro educativo, } \\
\text { por tanto, es indispensable la } \\
\text { presencia de la familia en las ac- } \\
\text { tividades escolares. Es decir, que } \\
\text { la integración y participación es } \\
\text { fundamental. }\end{array}$ \\
\hline
\end{tabular}

Cuadro 1. Triangulación sujeto significante 1. 


\begin{tabular}{|c|c|c|c|}
\hline Cat. & Sujeto2 : Representante & Teorías & $\begin{array}{l}\text { Resumen conclusivo del } \\
\text { investigador }\end{array}$ \\
\hline 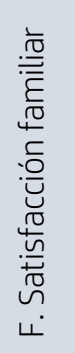 & $\begin{array}{l}\text { Dice que su hija es muy } \\
\text { obediente. Contraria a las } \\
\text { opiniones de otras ma- } \\
\text { dres que expresan lo } \\
\text { opuesto de sus hijos. }\end{array}$ & $\begin{array}{l}\text { Según Barraca, J y López, L } \\
\text { (2003) el concepto de satisfacción } \\
\text { familiar se define como "el resul- } \\
\text { tado del juego de interacciones } \\
\text { que se dan en el plano familiar" (p. } \\
\text { 319). }\end{array}$ & $\begin{array}{l}\text { El buen comportamiento de } \\
\text { los hijos es motivo de satisfac- } \\
\text { ción para los padres, y esto } \\
\text { pasa cuando se ha sabido dar } \\
\text { buena crianza. De la misma } \\
\text { forma, la obediencia forma } \\
\text { parte de los valores y disci- } \\
\text { plina que se da en el hogar. }\end{array}$ \\
\hline $\begin{array}{l}\frac{0}{0} \\
\frac{\pi}{0} \\
\frac{0}{3} \\
ن \\
ن\end{array}$ & $\begin{array}{l}\text { Expresa que el mal com- } \\
\text { portamiento de los niños } \\
\text { se debe a la falta de } \\
\text { atención de los padres } \\
\text { hacia sus hijos y falta } \\
\text { educación en el hogar. }\end{array}$ & $\begin{array}{l}\text { Cuidar es una clase de preocupa- } \\
\text { ción afirma Van, M (2002), por ello } \\
\text { tiene elementos invisibles, intan- } \\
\text { gibles, difíciles de contabilizar. } \\
\text { Una revisión de la literatura re- } \\
\text { ciente encontró tres componentes } \\
\text { críticos en el cuidado familiar: la } \\
\text { comunicación, la toma de decisio- } \\
\text { nes y la reciprocidad (p. 12) }\end{array}$ & $\begin{array}{l}\text { El cuidado y supervisión de los } \\
\text { hijos y hasta de la familia en } \\
\text { general, forma parte de la } \\
\text { atención que los responsables } \\
\text { han de darle a los menores. } \\
\text { Por lo que en concordancia con } \\
\text { lo que establece el autor y el } \\
\text { sujeto 2, el elemento es el } \\
\text { "cuidado" }\end{array}$ \\
\hline 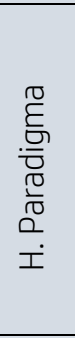 & $\begin{array}{l}\text { Dice que el modelo de } \\
\text { los hijos son los padres y } \\
\text { por eso han de tener un } \\
\text { excelente comporta- } \\
\text { miento que les permita } \\
\text { seguir ese ejemplo para } \\
\text { el futuro. }\end{array}$ & $\begin{array}{l}\text { Bunge, M (2001), en el Diccionario } \\
\text { de Filosofía, concibe paradigma } \\
\text { como un vocablo polisémico que } \\
\text { significa "parangón", "ejemplar", } \\
\text { "modelo a imitar", "enfoque habi- } \\
\text { tual", "estilo de pensamiento", en- } \\
\text { tre otros (p. 159) }\end{array}$ & $\begin{array}{l}\text { El modelo o ejemplo que los } \\
\text { padres quieren que los hijos si- } \\
\text { gan es el mejor, por lo que ha } \\
\text { de tener el mejor comporta- } \\
\text { miento, ya que los hijos siem- } \\
\text { pre actúan de acuerdo a lo que } \\
\text { observan durante su creci- } \\
\text { miento. }\end{array}$ \\
\hline 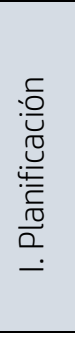 & $\begin{array}{l}\text { Cuando ambos padres } \\
\text { trabajan es buena idea } \\
\text { planificar el tiempo para } \\
\text { dedicarles a los hijos. Hay } \\
\text { que sacar tiempo para } \\
\text { ellos. }\end{array}$ & $\begin{array}{l}\text { La planificación en palabras de } \\
\text { Mestre, J (2004) debe ser enten- } \\
\text { dida como “un proceso encami- } \\
\text { nado a la consecución de unos re- } \\
\text { sultados determinados con ante- } \\
\text { rioridad, partiendo de unas nece- } \\
\text { sidades y ajustándose a los me- } \\
\text { dios disponibles" (p. 26) }\end{array}$ & $\begin{array}{l}\text { En la actualidad, casi en todos } \\
\text { los hogares ambos padres tra- } \\
\text { bajan, por lo que el tiempo } \\
\text { para los hijos se acorta. Sin } \\
\text { embargo, así sea poco, pero } \\
\text { que haya calidad en el tiempo. }\end{array}$ \\
\hline
\end{tabular}

Cuadro 2. Triangulación sujeto significante 2.

\section{Filtros Epistemológicos (categorización)}

\begin{tabular}{|l|l|c|l|l|}
\hline Texto & Propiedades & Categoría & Significado & Intrepretación \\
\hline $\begin{array}{c}\text { Porque tú sabes que } \\
\text { hay padres llevade- } \\
\text { ros, responsables y } \\
\text { que están pendiente } \\
\begin{array}{c}\text { pues, de la cuestión } \\
\text { en la escuela, pero } \\
\text { hay otros que hay } \\
\text { que cargarlos definiti- } \\
\text { vamente arriados y } \\
\text { eso es tedioso }\end{array}\end{array}$ & $\begin{array}{c}\text { Actuaciones } \\
\text { Productivo } \\
\text { Compromiso }\end{array}$ & $\begin{array}{c}\text { Aesponsa- } \\
\text { bilidad }\end{array}$ & $\begin{array}{l}\text { Es comprome- } \\
\text { terse con acciones } \\
\text { que se imponen } \\
\text { para obtener sa- } \\
\text { tisfacción. }\end{array}$ & $\begin{array}{l}\text { El compromiso es inhe- } \\
\text { rente a las personas res- } \\
\text { ponsables y que desean } \\
\text { un mejor porvenir tanto } \\
\text { para ellas como para su } \\
\text { entorno. }\end{array}$ \\
\hline
\end{tabular}




\begin{tabular}{|c|c|c|c|c|}
\hline $\begin{array}{c}\text { ah pues, si todos los } \\
\text { años escolares salen } \\
\text { más terribles que } \\
\text { obedientes y discipli- } \\
\text { nados. }\end{array}$ & $\begin{array}{c}\text { Orden } \\
\text { Control } \\
\text { Transparencia } \\
\text { Reglamenta }\end{array}$ & $\begin{array}{c}\text { B } \\
\text { Disciplina }\end{array}$ & $\begin{array}{l}\text { Ser disciplinado } \\
\text { significa seguir re- } \\
\text { glas, normas y ac- } \\
\text { tuar bien consigo } \\
\text { mismo y con la } \\
\text { sociedad. }\end{array}$ & $\begin{array}{l}\text { La disciplina en el ámbito } \\
\text { educativo tiene su impor- } \\
\text { tancia en la forma de } \\
\text { realizar las acciones que } \\
\text { conciben a la persona } \\
\text { como un ser de buena } \\
\text { conducta. }\end{array}$ \\
\hline $\begin{array}{l}\text { Yo sé, que aquí tene- } \\
\text { mos responsabilidad, } \\
\text { pero desde la casa se } \\
\text { inculcan los principios } \\
\text { mija y parece que es- } \\
\text { tos de ahora no tie- } \\
\text { nen nada. }\end{array}$ & $\begin{array}{l}\text { Cultura } \\
\text { Educación } \\
\text { Aptitud } \\
\text { Relevancia }\end{array}$ & $\begin{array}{c}\text { C } \\
\text { Valores }\end{array}$ & $\begin{array}{l}\text { Tienen su signifi- } \\
\text { cado en las apti- } \\
\text { tudes y actitudes } \\
\text { por medio de las } \\
\text { cuales el individuo } \\
\text { actúa. }\end{array}$ & $\begin{array}{l}\text { Los valores se expresan } \\
\text { a través de lo que se } \\
\text { aprende en el entorno fa- } \\
\text { miliar, y es por eso que } \\
\text { dicen mucho de la forma } \\
\text { de convivencia que se } \\
\text { lleva y de lo que el niño } \\
\text { puede expresar. }\end{array}$ \\
\hline $\begin{array}{l}\text { Le dije que se cal- } \\
\text { mara y me escuchara } \\
\text { para poder resolver }\end{array}$ & $\begin{array}{l}\text { Conocimiento } \\
\text { Pertinencia } \\
\text { Transparencia } \\
\text { Comunicación } \\
\text { Alternativas } \\
\text { Utilidad }\end{array}$ & $\begin{array}{l}\text { D } \\
\text { Resolución } \\
\text { de conflic- } \\
\text { tos }\end{array}$ & $\begin{array}{l}\text { Resolver los con- } \\
\text { flictos significa te- } \\
\text { ner paz y transmi- } \\
\text { tirla a través de la } \\
\text { comunicación y de } \\
\text { estrategias que } \\
\text { sirvan para vivir } \\
\text { en armonía. }\end{array}$ & $\begin{array}{l}\text { El camino de la resolu- } \\
\text { ción de conflictos no es } \\
\text { otra cosa que la expre- } \\
\text { sión adecuada de estas } \\
\text { emociones, la escucha de } \\
\text { las de los demás y la } \\
\text { búsqueda de alternativas } \\
\text { válidas para los que ex- } \\
\text { perimentan el conflicto. }\end{array}$ \\
\hline $\begin{array}{l}\text { siempre y cuando los } \\
\text { padres asistan, por- } \\
\text { que la verdad es que } \\
\text { son más dejados, o } \\
\text { sea, algunos actúan } \\
\text { como si no les impor- } \\
\text { tara la educación y } \\
\text { comportamiento de } \\
\text { sus hijos. }\end{array}$ & $\begin{array}{l}\text { Relevancia } \\
\text { Sentido de } \\
\text { pertenencia } \\
\text { Participación }\end{array}$ & $\begin{array}{c}\text { E } \\
\text { Integra- } \\
\text { ción fami- } \\
\text { liar }\end{array}$ & $\begin{array}{l}\text { Integrar es unifi- } \\
\text { car, y para el en- } \\
\text { torno familiar es } \\
\text { unir criterios de } \\
\text { forma integral y } \\
\text { sistémica. Es unir } \\
\text { esfuerzos para las } \\
\text { mejores alternati- } \\
\text { vas de solución. }\end{array}$ & $\begin{array}{l}\text { Supone un logro para la } \\
\text { familia. La integración de } \\
\text { todo el grupo familiar es } \\
\text { el ideal de todos. En el } \\
\text { entorno educativo la in- } \\
\text { tegración familiar es el } \\
\text { factor que causa los } \\
\text { avances significativos de } \\
\text { los hijos. }\end{array}$ \\
\hline
\end{tabular}

Cuadro 3. Filtro para Sujeto 1. Profesora. Fuente: Infante, Armada y Sinche (2018). Tomado de: Leal, J (2012).

\begin{tabular}{|c|c|c|l|l|}
\hline Texto & Propiedades & Categoría & Significado & Intrepretación \\
\hline $\begin{array}{c}\text { ella es una niña muy } \\
\text { obediente y respon- } \\
\text { sable con sus cosas. } \\
\text { Yo digo que Dios nos } \\
\text { premió con esta ben- } \\
\text { dición }\end{array}$ & $\begin{array}{c}\text { Significativo } \\
\text { Complaciente } \\
\text { Bienestar } \\
\text { Prosperidad }\end{array}$ & $\begin{array}{c}\text { F } \\
\text { Satisfac- } \\
\text { ción fami- } \\
\text { liar }\end{array}$ & $\begin{array}{l}\text { Es el hecho de } \\
\text { que las situacio- } \\
\text { nes que ocurran } \\
\text { en el entorno fa- } \\
\text { miliar sean pro- } \\
\text { ductivos y benefi- } \\
\text { cien la relación de } \\
\text { la familia. }\end{array}$ & $\begin{array}{l}\text { Cuando los hechos de la } \\
\text { familia son llevaderos, es } \\
\text { decir, que se viva en un } \\
\text { ambiente sano, afectivo y } \\
\text { asertivo, es un hecho que } \\
\text { hay satisfacción. }\end{array}$ \\
\hline $\begin{array}{c}\text { a mi manera de ver } \\
\text { las cosas tiene que } \\
\text { ser por falta de aten- } \\
\text { ción y educación } \\
\text { profe }\end{array}$ & $\begin{array}{c}\text { Supervisión } \\
\text { Interés } \\
\text { Intervención }\end{array}$ & G & $\begin{array}{l}\text { Es el deber del } \\
\text { ser humano como } \\
\text { tal, cuidarsey ydo } \\
\text { contribuir en el } \\
\text { cuidado de su en- } \\
\text { torno. }\end{array}$ & $\begin{array}{l}\text { Importa tener el interés } \\
\text { de hacer las cosas y que } \\
\text { se haga de forma filan- } \\
\text { trópica. }\end{array}$ \\
\hline
\end{tabular}




\begin{tabular}{|c|c|c|l|l|}
\hline $\begin{array}{c}\text { Aparte de eso, está el } \\
\text { ejemplo de nosotros } \\
\text { como padres que de- } \\
\text { bemos darle a los hi- } \\
\text { jos. }\end{array}$ & $\begin{array}{c}\text { Claridad } \\
\text { Esquema }\end{array}$ & Paradigma & $\begin{array}{l}\text { Es el modelo que } \\
\text { se desea seguir } \\
\text { como forma de } \\
\text { orientar un ca- } \\
\text { mino. }\end{array}$ & $\begin{array}{l}\text { Todos los patrones que } \\
\text { conciban pueden ser los } \\
\text { que contribuyan o no a } \\
\text { conformar la base del fu- } \\
\text { turo, sea positiva o nega- } \\
\text { tiva. }\end{array}$ \\
\hline $\begin{array}{c}\text { Poniéndole cuidado, } \\
\text { trabajan todo el día, } \\
\text { bueno que se planifi- } \\
\text { quen para tener el } \\
\text { tiempo que necesitan } \\
\text { los niños }\end{array}$ & $\begin{array}{c}\text { Orientación } \\
\text { Sistematiza- } \\
\text { ción } \\
\text { Acciones } \\
\text { Dirección } \\
\text { Organización }\end{array}$ & $\begin{array}{c}\text { Planifica- } \\
\text { ción }\end{array}$ & $\begin{array}{l}\text { Es la disposición } \\
\text { que tiene el indivi- } \\
\text { duo por hacer } \\
\text { bien su trabajo, de } \\
\text { forma ordenada y } \\
\text { sistemática. }\end{array}$ & $\begin{array}{l}\text { Planificar el tiempo es } \\
\text { necesario en función de } \\
\text { lograr lo que se quiere } \\
\text { para una vida ordenada y } \\
\text { congruente. }\end{array}$ \\
\hline
\end{tabular}

Cuadro 4. Filtro para Sujeto 2. Representante. Fuente: Infante, Armada y Sinche (2018). Tomado de: Leal, J (2012).

\section{DISCUSIÓN}

Cuando se habla sobre la orientación de padres y representantes en la formación de sus hijos, se hace referencia específicamente a la educación que se deriva del hogar, en donde todo ese entorno que le rodea es de suma importancia para el bienestar y desarrollo integral del individuo. Se realiza de manera temprana toda la intervención posible para lograr los patrones deseados por la demanda social, y que además de ello sirve como base para futuras generaciones, en donde los principios y conductas deseables son el modelo a seguir.

Pocos son los padres que en la actualidad tienen el tiempo que demandan los hijos en su crianza, sin embargo, esto es solo cuestión de planificación, y como se había dicho ya en el desarrollo de la investigación, no se trata de todo el tiempo, sino que el que se le otorgue sea provechoso y de calidad para todos. Se trata de contribuir en el desarrollo de los hijos de forma efectiva y eficaz, que el tiempo que se les brinde sea significativo para ellos, esto deja a corto, mediano y largo plazo, gratas experiencias de ese compartir.

Cabe agregar, de acuerdo a estudios realizados, que los padres deben recibir ciertas orientaciones por parte de los docentes, ya que sus hijos pasan un tiempo significativo al lado de ellos, y a través de sus diagnósticos, el docente puede observar e interpretar situaciones que ameritan la intervención positiva de padres y representantes, por lo que se considera necesario que la comunicación entre estos sea fluida y consecuente. Esto significa, niños más obedientes, productivos, felices y con una capacidad cognitiva más desarrollada para ser aprovechada en función de su futuro educativo y profesional. La motivación por parte del docente también es indispensable en este caso, ya que hay padres que se niegan constantemente a asistir a reuniones y a participar en los programas que evidentemente ayudaran a sus hijos. Esto se puede lograr con invitaciones por medio de trípticos y folletos. 


\section{CONCLUSIONES}

De acuerdo al estudio, se pueden considerar finalmente con especial relevancia que: El sistema familiar compuesto por padres y representantes en el ámbito educativo, actúa sobre la escuela siempre y cuando el niño sea portador de valores y conductas que reflejen su medio familiar.

- Los padres son los que pueden promover el vínculo y la integración con la institución, al estar motivados por la educación y desarrollo de su estirpe.

- El desarrollo integral del niño junto a la calidad de la educación que reciben desde la educación inicial es el fin primordial del proceso educativo como tal.

- Se evidenció que en ocasiones los padres no se encuentran preparados para afrontar la realidad educativa, es decir, carecen de esa preparación que influye significativamente en los hijos.

- Hay entornos familiares con grandes necesidades que requieren de orientación para cumplir de manera acertada la tarea y enorme responsabilidad de ser padres, y que además compartan con los docentes de una forma asertiva.

- De acuerdo a los propósitos de la investigación se pudo lograr la realización del programa y llevar a cabo cada uno de los temas que se propusieron, orientados a la formación de padres y representantes en las diversas áreas que se abarcaron.

\section{REFERENCIAS}

BARRACA, J. \& LÓPEZ, L. (2003). Escala de Satisfacción familiar por adjetivos. Madrid: Publicaciones de Psicología Aplicada. [Trabajo de grado en línea]. Recuperado de: [Enlace].

BUNGE, M (2001). Diccionario de Filosofía. Siglo XXI Editores, S.A de C.V. Tercera Edición. ISBN: 968-23-2276-6. [Libro en línea]. Recuperado de: [Enlace].

FISCHER, G (1992). Campos de Intervención en Psicología Social. NARCEA, S.A de Ediciones. Madrid - España. ISBN: 84-277-0976-5. [Libro en línea]. Recuperado de: [Enlace].

GRAU, M.D. (2004). Escuela de padres: un programa de formación/prevención. Educar. Recuperado de: [Enlace].

HERNÁNDEZ, C Y LÓPEZ, J (2002). Disciplinas. Primera Edición. Instituto Colombiano para el Fomento de la Educación Superior (ICFES). [Trabajo en línea]. Recuperado de: [Enlace].

JORNADAS DE ESTUDIO: INTEGRACIÓN EN FAMILIA (2011). Procesos y tendencias. La familia, clave de la integración. ISBN: 978-84-936928-9-6. [Libro en línea]. 
MESTRE, J (2004). Planificación deportiva: teoría y práctica. INDE Publicaciones. Tercera Edición. Barcelona - España. ISBN: 84-87330-39-8. [Libro en línea]. Recuperado de: [Enlace].

NÚÑEZ, M (2013). Escuela para padres. El ideal de un movimiento que necesita repotenciarse. [Página en línea]. Recuperado de: [Enlace].

VALDEZ, M Y GUERRA, E (s/f). Mediación y resolución de conflictos. [Documento en línea].

VAN, M (2002). Care-as-Worry, or Don`t Worry, Be Happy. Qual Health Res. [Página en línea].

WESTER, J. H. (2008). "Dimensiones y retos de una educación para la responsabilidad ciudadana”. Utopía y praxis latinoamericana. № 42. Revista Internacional de Filosofía Iberoamericana y Teoría Social. CESA-FCES, Universidad del Zulia. Maracaibo-Venezuela. [Trabajo en línea]. Recuperado de: [Enlace]. 